Fecha de recepción: junio 2020

Fecha de aceptación: julio 2020

Versión final: septiembre 2020

\section{Cómic, memoria histórica y activismo LGTB en diálogo: el ejemplo de la novela gráfica El Violeta \\ Joan Sapiña ${ }^{(1)}$ y Ana Belén Cao Míguez ${ }^{(2)}$}

Resumen: El propósito de este trabajo es mostrar cómo la novela gráfica El Violeta (2019) constituye un interesante ejemplo de diálogo entre el medio artístico del cómic, la memoria histórica y el activismo LGTB, al generar una experiencia colectiva homosexual del franquismo que resulta especialmente oportuna en el contexto de debate en torno al pasado reciente que vive la sociedad española en la actualidad. A partir de diversos testimonios individuales, este cómic emprende una reconstrucción ficcional de la violencia física y simbólica ejercida por el régimen franquista que conforma un lugar de la memoria narrativo de una experiencia traumática común, frecuentemente silenciada o invisibilizada. La obra que aquí se analizará contribuye, pues, a configurar la memoria histórica de los homosexuales que sufrieron la dictadura, plasmando, a través del lenguaje comicográfico, la homofobia represiva del régimen. Así, a falta de una plena reparación jurídica e institucional, supone al menos una tentativa de reconocimiento simbólico en el plano sociocultural.

Palabras clave: homosexualidad - represión - cómic - memoria histórica - testimonio.

[Resúmenes en inglés y portugués en la página 171]

(1) Doctorando en Lingüística Teórica y Aplicada en la UCM, obtuvo el máster en Profesorado de Secundaria y la licenciatura en Filología Hispánica por la UA. Además, es posgraduado en Literatura Comparada y Estudios Culturales por la Fundación ADEIT-UV. Ha desempeñado labores docentes en diferentes centros universitarios de Portugal: el IPP, el IPB y la UTAD.

(2) Doctora en Estudios Literarios Comparados por la UNL, licenciada en Filología Hispánica por la USAL y licenciada en Filología Portuguesa por la USC, donde también obtuvo el DEA en Teoría de la Literatura y Literatura Comparada. Docente en la UBI desde 2004, es investigadora integrada del Communication and Media Group (LabCom-UBI) e investigadora asociada en el Centre for the Humanities (CHAM-FCSH-NOVA). 


\section{Introducción}

En este trabajo nos proponemos analizar la novela gráfica titulada El Violeta como ejemplo de diálogo entre el medio artístico del cómic, la memoria histórica y el activismo LGTB. Publicada en septiembre de 2018 por el sello Drakul de Fuenlabrada (Madrid), esta obra es el fruto de la colaboración de tres autores: Juan Sepúlveda Sanchis, Antonio Santos Mercero (guión) y Marina Cochet (dibujo y maquetación). Señal de la buena aceptación del cómic es el hecho de que, en enero de 2019, transcurridos pocos meses de la primera edición, saliese ya a la luz una segunda en tapa dura, que es la que hemos manejado en este caso (Sepúlveda Sanchis et al., 2019).

El enfoque teórico-metodológico que seguiremos se sitúa en el campo de los Estudios Culturales y, por lo tanto, nos moveremos dentro un marco en el que "la cultura es simultáneamente concebida como objeto de estudio y como lugar de posicionamientos críticos e ideológicos" (Juan-Navarro y Torres-Pou, 2008, p. 10). El carácter interdisciplinar de los Estudios Culturales nos permitirá abordar el cómic que constituye nuestro objeto de estudio desde una perspectiva que concilie cuestiones relativas tanto a la identidad de género y orientación sexual como a la memoria histórica.

Así, nuestro propósito es encarar El Violeta como un artefacto cultural que despliega una serie de mecanismos de recuperación de la memoria histórica LGTB. Más concretamente, trataremos de observar el modo en el que esta novela gráfica retrata la homofobia institucional y social de la dictadura, generando de esa forma una experiencia colectiva homosexual del franquismo y un alegato contra el olvido que responde a una de las reivindicaciones del colectivo LGTB en los últimos años, como queda de manifiesto en el lema del Orgullo de 2019: “Mayores sin armarios: ¡Historia, Lucha y Memoria!”.

\section{La era de la memoria}

La sociedad española lleva al menos dos décadas debatiéndose con su doloroso pasado reciente, con la puesta en marcha de un proceso de amplia dimensión -dado su alcance social, político, jurídico, legal, institucional, cultural, historiográfico- conocido como "recuperación de la memoria histórica". Tal como ocurre en otros espacios geoculturales que han vivido experiencias traumáticas colectivas más o menos análogas, se trata de un fenómeno que implica un conflicto entre (re)interpretaciones del pasado fuertemente incardinadas en el presente de diferentes grupos, cada uno de los cuales "elabora la representación del pasado que mejor se adecua a sus valores e intereses" (Sevillano Calero, 2003, p. 298). En el caso español, el choque resulta aún mayor dada la anómala política de la memoria de la Transición, que consistió, en realidad, en una política de la amnesia (Reig Tapia, 2009).

No sorprende, por ello, el importante espacio mediático que han venido ocupando las discusiones al respecto de este proceso, tanto en los años que precedieron como, muy especialmente, en los que siguieron a la aprobación de la comúnmente llamada Ley de la Memoria Historia; esto es, la Ley 52/2007, de 26 de diciembre, "por la que se reconocen y 
amplían derechos y se establecen medidas en favor de quienes padecieron persecución o violencia durante la guerra civil y la dictadura". Pese a sus limitaciones, esta ley convierte a España en el primer país que reconoce a las minorías sexuales entre las víctimas del Estado (Huard, 2019, p. 104). España entra, así, más de treinta años después de la muerte del dictador, en lo que Julián Casanova denominó la "era de la memoria" sobre el franquismo: una era "incómoda para muchos" en la medida en que supone "el regreso del pasado oculto y reprimido" (Casanova, 2014).

Lo que hemos convenido en llamar "memoria histórica" no solo produce incomodidad o incluso abierto rechazo en algunos sectores como, además, genera multitud de controversias en el ámbito académico, empezando por el propio concepto y la (in)oportunidad de tal (oximorónica) designación, puesto que se conjugan en ella dos conceptos relacionados, pero distintos y hasta incompatibles: memoria e historia. De dichas incongruencias teóricas se han ocupado, entre muchos otros autores, Ruiz-Vargas (2008) y Erice Sebares (2008), quienes, tras revisar y discutir las aportaciones de estudiosos de referencia como Maurice Halbwachs, Paul Ricoeur, Pierre Nora o Enzo Traverso, admiten que el término memoria histórica carece de justificación epistemológica. Aun así, ambos defienden la legitimidad y relevancia de la memoria histórica, pues, con independencia de lo anterior, "está cumpliendo una importante función social: mantener viva la memoria de las víctimas del franquismo hasta que sea reconocida su verdad, restituida su dignidad y reparado el daño moral que se infringió a ellas y se legó a sus descendientes” (Ruiz-Vargas 2008, p. 76).

Conviene subrayar dos rasgos característicos de la memoria histórica que ya pueden deducirse de lo expuesto hasta aquí. El primero de ellos está relacionado con la fuerte imbricación entre memoria individual y memoria colectiva, así como con el peso específico que desempeñan en su conformación los recuerdos y testimonios individuales (los de las víctimas o sus descendientes). Cabría en este sentido hablar, de hecho, de una "memoria autobiográfica de la historia" (Ruiz-Vargas, 2008, p. 72). Por otro lado, la memoria histórica implica, como toda memoria social, "una conceptualización crítica de acontecimientos de signo histórico compartidos colectivamente y vivos en el horizonte referencial del grupo" (Colmeiro, 2005, p. 18); es decir, posee una "naturaleza auto-reflexiva sobre la función de la memoria", en tanto que los hechos que la conforman "van acompañados de una conciencia de su propia necesidad como testimonio histórico" (Colmeiro, 2005, p. 18). En definitiva, la memoria histórica es "una construcción social del recuerdo, que evoca con otros instrumentos, y a veces deforma, lo que los historiadores descubrimos" (Casanova, 2014) porque se trata de una "rectificación simbólica de la historia" reivindicada por las "minorías marginadas durante años" y con una consciente aspiración rehabilitadora (Sánchez Marcos [y Sánchez Costa] ${ }^{1}, 2012$, p. 181).

\section{La memoria (re)construida desde la cultura: el cómic, un arte comprometido}

Es innegable que el reconocimiento social de los crímenes cometidos durante la guerra civil y la dictadura solo puede proporcionarlo el derecho, con la garantía del sistema po- 
lítico (Resina y Winter, 2017). De forma paralela, y sobre todo mientras esa reparación pública, jurídico-política, no se desarrolla plenamente, existe también un "deber de justicia retributiva-reparadora" que "recae en los demás actores sociales, o sea, las ciencias y la cultura" (Resina y Winter, 2017, pp. vii-viii). Por lo tanto, los discursos emanados desde el último ámbito mencionado pueden actuar como cajas de resonancia social de la memoria (Resina y Winter, 2017, p. viii); del mismo modo, productores literarios, artistas plásticos, cineastas, guionistas y dibujantes pueden convertirse en actores sociales de la memoria. Los autores citados (Resina y Winter, 2017) toman de Pierre Nora el concepto de lugar de la memoria entendiéndolo de una forma amplia, de tal manera que quepan en él productos discursivos como documentos, textos, películas o, añadimos nosotros, cómics. Quiere decirse que las obras comicográficas, al igual que otros productos culturales, pueden convertirse -lo han hecho ya- en lugares de la memoria; esto es, en oportunidades de cumplimiento de las aspiraciones de los sujetos colectivos en lo que concierne a la re/ construcción del pasado (Resina y Winter, 2017, pp. I-II).

En efecto, con la literatura, la pintura o el cine, el cómic es uno de los lenguajes artísticos que "ha mostrado su vigor subversivo al plantear interrogantes, al cuestionar y desestabilizar las representaciones del pasado", configurando "un artefacto de memoria colectiva capaz de transmitir las preocupaciones propias de artistas que impregnan su obra de una mirada responsable con el entorno" (Souto y Martínez Rubio, 2016, p. 2). Teniendo en cuenta que los recuerdos individuales "se hacen sociales y contribuyen a crear y reforzar la identidad del grupo" precisamente a través de la narración (Ruiz-Vargas, 2008, p. 70), las artes narrativas son particularmente eficaces a este respecto. Ocurre además que, según afirman Luz Souto y José Martínez Rubio (2016), el cómic, a diferencia de otros medios (pero al igual que algunas manifestaciones afines como el humor gráfico o los memes), presenta "el plus de alcanzar a un público más amplio", lo cual lo convierte en un "soporte idóneo para la reflexión sobre determinados hechos históricos, procesos traumáticos o temas sociales, cuando no de punta de lanza de discursos más elaborados o de posiciones políticas que los sostienen y que los generan” (Souto y Martínez Rubio, 2016, pp. 2-3).

Este es el mismo argumento esgrimido por Manuel de la Fuente Soler para explicar una tendencia que puede observarse tanto en el cómic internacional como en el nacional: la oportunidad que brinda el cómic de "mantener abierto un debate político muchas veces relegado al olvido" se ve acrecentada por "el potencial de una clara penetración social" que le viene dado por su condición de "medio de comunicación de masas" (de la Fuente Soler, 2011, p. 275). También David Fernández de Arriba (2015) está convencido de la validez del cómic como medio de recuperación de la memoria histórica. En la defensa de este punto de vista, apunta "tres grandes virtudes" de la historieta: la versatilidad, la accesibilidad, "ya que la presencia de dibujo y otros elementos visuales lo hace atractivo para muchas personas a la que un libro de Historia alejaría de la materia", y por último, "la implicación total del autor, ya que es su visión de la historia la que vemos reflejada", aunque "como toda obra artística, es necesario que el autor tenga la voluntad de documentarse o de ser fiel a los relatos de las personas que participaron en determinados hechos" (Fernández de Arriba, 2015, p. 29).

No es de extrañar, así, el creciente corpus de cómics que, restringiéndonos al ámbito español, se centran en la guerra civil o el franquismo ${ }^{2}$. Existe igualmente un volumen con- 
siderable de estudios que se detienen en estos cómics (v. gr.: Alary, 2016; Bórquez, 2016; Fernández de Arriba, 2015; Matly, 2014; Nonnenmacher, 2006) o que, desde otro tratamiento de la relación entre el medio comicográfico y esa misma etapa del pasado reciente, se proponen examinar las historietas como fuente historiográfica (Gual Boronat, 2013) o encararlas como herramienta didáctica (Fernández de Arriba, 2019).

A este interés por parte de los investigadores contribuye notablemente el reconocimiento que el medio comicográfico va adquiriendo en el mundo académico, en buena medida gracias, precisamente, a la existencia de publicaciones destinadas a consumidores adultos y que, sin perder su carácter de producto de entretenimiento, tocan asuntos serios como el que aquí nos ocupa. Conviene destacar el papel que, a este propósito, le cupo a una novela gráfica que justamente representa, casi por antonomasia, este género de "historietas de la memoria", como propone denominarlas Néstor Bórquez (2016): nos referimos a Maus. A Survivor's Tale, de Art Spiegelman, ganadora del Pulitzer en 1992, hecho que marca un antes y un después en la consagración del medio (García, 2010).

\section{Hacia una memoria histórica LGTB}

Se calcula que fueron unas cinco mil las personas que padecieron la represión del franquismo por su orientación o identidad sexual, primero al amparo de la Ley de Vagos y Maleantes (LVM, 1954) y, más tarde, de la Ley de Peligrosidad y Rehabilitación Social (LPRS, 1970). A estos presos sociales de la dictadura nunca les llegó ni el indulto ni la amnistía, como sí ocurrió con los presos políticos. Es más, las persecuciones al colectivo LGTB se mantuvieron en la Transición e incluso buena parte de la democracia, especialmente entre los grupos más vulnerables del colectivo (prostitutos, trans y homosexuales humildes o sin profesión), que frecuentemente eran detenidos en la calle y, tras la reforma de la LPRS de diciembre de 1978, absueltos (Terrasa Mateu, 2016). En cuanto al (tardío) reconocimiento de la condición de víctimas del Estado para estas personas por parte de los poderes públicos, el primer hito se dio en diciembre de 2004, con una declaración institucional del Congreso de los Diputados que tenía por finalidad su "rehabilitación moral"3.

En lo que respecta a la reparación económica, durante el gobierno del socialista José Luis Rodríguez Zapatero fue aprobada una disposición adicional a la Ley de Presupuestos Generales del Estado de 2009 para poder dar cumplimiento a lo dispuesto en la Ley 52/2007. El primero de los indemnizados, con 4.000 euros, fue el valenciano Antoni Ruiz, presidente de la Asociación de Ex-Presos [sic] Sociales. Desde entonces (2009), apenas 127 personas pudieron beneficiarse de estas (pírricas) indemnizaciones (Ruiz, 2018) ${ }^{4}$. Excluyendo a las víctimas ya fallecidas, ese número tan reducido de indemnizaciones se debe en parte a que, en el año 2012, el Gobierno del Partido Popular fijó un plazo límite (31 de diciembre de 2013), no previsto inicialmente, para presentar las solicitudes, lo que provocó la protesta de la Asociación de Ex-Presos Sociales: desde esta asociación se recordaba la dificultad que suponía para los demandantes reunir los documentos probatorios necesarios, muchas veces ilocalizables o hasta destruidos. Asimismo, y aunque los antecedentes penales por condenas relacionadas con las leyes franquistas ya estén cancelados (motivo por el 
que inició su lucha Antoni Ruiz en 1995), el sistema informático de la policía todavía deja constancia del paso por prisión de estas víctimas (Ruiz, 2018). Todo ello explica, en fin, el desencanto que a este respecto transmite Antoni Ruiz (Ruiz, 2018; Huard, 2019, p. 104). También Vallès Muñío (2017) nota que los presos sociales del franquismo no solo recibieron indemnizaciones de menor cuantía en relación a los presos políticos, sino que, además, a diferencia de estos, el período pasado en prisión no les fue computado como tiempo activo en la seguridad social.

Por otra parte, la legislación sobre memoria histórica desarrollada tanto por el gobierno central como por las comunidades autónomas ha obviado frecuentemente el patrimonio y los lugares de la memoria relacionados con la comunidad LGTB. Las pocas comunidades que preveían la creación de centros de documentación LGTB no han llegado a crearlos (Fernández-Paradas, 2020, p. 13), pese al gran perjuicio que ello supone para la investigación (Terrasa Mateu, 2016, pp. 516-520), por lo que actualmente nos hallamos ante un abandono de los lugares de la memoria LGTB. Dos de los más destacados se plasman, justamente, en El Violeta: la "colonia agrícola" de Tefía, por un lado, y las cárceles que albergaban galerías para "invertidos", por otro. El primero de esos lugares es hoy un albergue que apenas dispone de una placa explicativa, cuando "debería ser un museo de la memoria histórica LGTB” (Sepúlveda, 2018). En cuanto a los segundos, cabe destacar el estado deplorable en el que se encuentran espacios tan relevantes como la cárcel de Huelva (Serrano, 2017), que durante el franquismo concentró a un gran número de reclusos homosexuales y que fue declarada Lugar de la Memoria por la Junta de Andalucía en 2013. Como podemos comprobar, no parece que a las víctimas LGTB de la represión franquista les haya llegado la plena reparación que legítimamente reclaman por la vía de la Justicia y del poder político, ni tampoco que exista un apoyo institucional para la recuperación y el cuidado del patrimonio y los lugares de la memoria LGTB. Es por ello, precisamente, que, a falta de otras formas más tangibles de resarcimiento, cobran tanta relevancia los otros actores sociales a los que se referían Resina y Winter (2017: vid. supra, apartado 2). El propio Antoni Ruiz (2018) destaca lo que por la recuperación de la memoria histórica de este colectivo están haciendo las publicaciones científicas, los medios de comunicación y las formas culturales tales como documentales o exposiciones fotográficas. En tal contexto, una "historieta de la memoria" (Bórquez, 2016) como El Violeta actúa también como caja de resonancia de la violenta represión, simbólica y física, ejercida durante el franquismo contra homosexuales e "invertidos" (Gutiérrez Dorado, 2008; Mora Gaspar, 2016).

La novela gráfica por la que aquí que nos interesamos pretende darle visibilidad a una parte de la memoria colectiva que los historiadores ya conocen (y han demostrado documentalmente), pero cuya divulgación fuera de esa (restricta) esfera resulta aún necesaria. De esa forma, El Violeta contribuye a inscribir en el espacio público, popularizándola, una porción de la memoria histórica poco conocida para el gran público y relativa a un grupo social cuya conciencia identitaria está, además, en construcción. También por esto último resulta imprescindible emprender esa evocación crítica del pasado, ya que la construcción de cualquier sujeto, individual o colectivo, va estrechamente ligada a su conciencia histórica: la imagen que ese "sujeto (individual o colectivo) posee de quién es depende, en buena medida, de cómo describe su trayectoria vital" (Sánchez Marcos [y Sánchez Costa], 2012, p. 180).En la recuperación de la memoria histórica LGTB, además del activismo de 
la ya referida Asociación de Ex-Presos Sociales, han desempeñado un papel fundamental los testimonios de las propias víctimas. Como señala Gutiérrez Dorado (2008), gracias a tales memorias individuales ha sido posible desvelar esa faceta oculta de la represión franquista, suscitando el interés entre los especialistas del derecho e historiadores $y$, sobre todo, en la opinión pública. A este respecto, ya hemos indicado anteriormente que la memoria histórica es una "memoria autobiográfica de la historia" (Ruiz-Vargas, 2008, p. 72). También la novela gráfica que aquí nos ocupa recurre al acervo testimonial de las personas represaliadas para poder emprender su particular acercamiento a la memoria histórica: un acercamiento que se realiza desde el cómic y desde la ficción.

En efecto, El Violeta es una narración explícitamente ficcional, protagonizada por personajes manifiestamente inventados (Sepúlveda Sanchis et al., 2019, p. 102), pero documentada y basada en hechos testimoniados por personas reales. Los autores del cómic no tienen una implicación directa en la historia narrada: no rememoran experiencias vividas en primera persona o transmitidas por su entorno familiar. En ese sentido, nos hallamos ante una "memoria recreada" (Fernández de Arriba, 2015) a partir de testimonios individuales que, al ficcionalizarse, conforman el relato de una experiencia común (colectiva). Tal ejercicio de memoria-ficción no solo pretende resultar verosímil, sino que asume también una función abiertamente testimonial. Además, en El Violeta nos vamos a encontrar con espacios y personajes que sí se vinculan a la realidad biográfica de uno de los guionistas, Juan Sepúlveda. Se trata, respectivamente, de la fábrica de turrones Los Golosos en la que trabaja el protagonista (Bruno) y de la tía de este, Julia, propietaria de dicha fábrica. De esa forma, aunque no se trate de una obra autobiográfica, el guionista se inscribe subjetivamente en la historia narrada, transfiere algo de su realidad familiar a la ficción, reforzando tal pacto de verdad con un recuso gráfico: la inclusión de fotografías de esos lugares y personas reales a modo de epílogo (Sepúlveda Sanchis et al., 2019, pp. 102-104).

\section{La represión contra 'los violetas': una memoria colectiva}

La novela gráfica que analizamos se desarrolla en un marco cronológico amplio (19551973), abarcando casi dos décadas en las que la sociedad española vive importantes cambios sociales y económicos: la incipiente salida del modelo autárquico de los 50, momento de superación de los peores años de la posguerra, da paso a la paulatina apertura del régimen franquista a las inversiones extranjeras durante los 60 y 70 , propiciando una ligera industrialización del país y la llegada del turismo europeo. Progresivamente, en estas décadas el movimiento antifranquista clandestino, principalmente comunista, se convierte en una fuerza opositora destacada, especialmente en núcleos urbanos, obreros y estudiantiles. Este contexto es determinante para comprender el predominio de elementos de violencia simbólica o física en El Violeta, pues el abandono del modelo autárquico conllevó una honda preocupación en el régimen por la corrupción de las costumbres españolas y "una obsesión inaudita por la codificación, patologización y contención de las actividades homosexuales" (Pérez Sánchez, 2004, p. 39). De hecho, el propio nombre de la novela gráfica recoge el término despectivo que el régimen profería hacia homosexuales y afeminados. A 
través de la narración de la vida de Bruno y Julián, los coprotagonistas, El Violeta recoge algunos de los principales elementos represivos del estado franquista, una represión que mantiene ciertas similitudes con la sufrida por los presos comunes o políticos, pero que contiene también una dimensión sexuada análoga, con sus peculiaridades, a la de las mujeres presas, especialmente las republicanas (Abad, 2009, p. 84; Vallès Muñío, 2017, p. 5). Se trata, pues, de una doble violencia, que incluye violaciones y prostitución carcelaria. Las instituciones y los mecanismos implicados en la represión franquista fueron diversos, pero siempre fundamentándose en el discurso jurídico y la ley. El marco jurídico bajo el cual se llevó a cabo la brutal represión sobre la población LGTB fue, al principio, la ya mencionada LVM, una ley que databa de la Segunda República y que, en el año 1954, fue alterada para incluir a los homosexuales ${ }^{5}$. En 1970, dados los cambios sociales acaecidos en los 50 y 60, el régimen pretendió actualizar esa represión con la aprobación de la LPRS (Fernández Asperilla, 2005 p. 13) ${ }^{6}$. El carácter represor hacia la comunidad LGTB se mantenía, pero la acción no se dirigía tanto al "homosexual" (LVM) como a los "actos homosexuales" (LPRS), sobre todo si concurrían otras situaciones (reincidencia, prostitución, etc.). El discurso jurídico homofóbico se completaba con la figura de "escándalo público" en el Código Penal, frecuentemente relacionada con la homosexualidad -así lo corroboraba el propio Tribunal Supremo-, que permaneció vigente hasta la reforma de 1988 (Martín Sánchez, 2011, pp. 256-257).

El marco legislativo homofóbico permitió una violencia sistemática contra personas LGTB, ya que la consideración de los homosexuales como "peligrosos sociales" por las leyes franquistas dejó un margen muy amplio de arbitrariedad para la imposición de duras medidas de seguridad (Pérez Sánchez, 2004, p. 44): redadas en parques y aseos de estaciones de autobuses (el caso de Anselmo en El Violeta) o emboscadas y encerronas de policías que se hacían pasar por homosexuales en bares o cines (como le ocurre a Bruno al inicio de la novela en el cine Ruzafa). Esta serie de trampas policiales pretendía lograr la detención de homosexuales y la delación de otros: el cómic nos muestra cómo llevan a "dar un paseíllo" a Bruno por parques para delatar a otros homosexuales, señalando a quien conociese bajo amenazas.

Una vez detenidos, los homosexuales se veían en ocasiones sometidos a palizas u obligados a firmar la confesión del crimen bajo tortura, y pasaban largas estancias en prisión. El sistema penitenciario franquista hacía de la cárcel un lugar muy poco seguro para presos LGTB, puesto que muchas veces sufrían violencia -incluida la sexual, como ya hemos indicado-, por parte tanto de policías como de otros reclusos (Caetano Pira, 2018). El Violeta refleja varios episodios de esta violencia sexual carcelaria, como por ejemplo cuando la Faraona, un influyente recluso de la prisión, compra a Bruno durante dos horas.

El elevado nivel de violencia sistemática, así como las penurias económicas y el hambre, podían llevar a algunas personas LGTB al suicidio, una decisión drástica que observamos en el personaje de "El morito", un bello joven prostituto, analfabeto, constantemente violado en la cárcel, a quien los guardianes confiscan la comida que había intentado hacerle llegar su novio británico. Debe notarse que, en la construcción de este personaje (las continuas vejaciones a las que es sometido, el detalle de las cuchillas que solicita mediante una carta), hallamos ciertas analogías con la historia vivida (y testimoniada) por una figura real: Francesc Oliver, La Rampova (Ruiz Mantilla, 2013). 
El sistema penitenciario franquista contemplaba frecuentemente la separación de los presos homosexuales en galerías diferentes (Huard, 2016, p. 140), pero además disponía de dos cárceles para homosexuales (Huelva y Badajoz), una para "pasivos" y otra para "activos" (Galván, 2017, p. 70)7. El sistema penitenciario también contaba con la "colonia agrícola" de Tefía, un campo de concentración ${ }^{8}$ en el desierto de la isla canaria de Fuerteventura para homosexuales y otros tipos de "vagos y maleantes". En esa colonia penitenciaria pasaban meses o años recluidos, bajo condiciones de penuria extrema, en un estricto régimen disciplinario militar y realizando trabajos forzados, como aparece retratado en el cómic a través de la vivencia de Julián.

Aparte de las numerosas medidas represivas recogidas en el cómic, cabe recordar otras que este no recrea de forma explícita, pero que fueron igualmente muy relevantes: era frecuente, por ejemplo, que 'los violetas' detenidos fuesen condenados a penas de destierro de sus ciudades natales (Terrasa Mateu, 2008, p. 97). Esa condena, unida a la discriminación laboral y el acoso policial constante, impedían que muchos pudiesen trabajar y, en consecuencia, se veían abocados a la prostitución, asemejándose, una vez más, al destino de tantas mujeres presas republicanas (Abad, 2009 p. 84). A su vez, el ejercicio de la prostitución, así como el origen humilde de muchos homosexuales, propiciaban que la policía los detuviese: como señala el investigador Geoffroy Huard, las detenciones de homosexuales durante el franquismo en Barcelona se cebaban con aquellos que no conseguían demostrar unos ingresos legales y un domicilio fijo, y con quienes hacían ostentación en la calle de su condición de "invertidos" (Huard, 2016, p. 150). Ese hincapié en perseguir la prostitución homosexual, y especialmente a jóvenes pobres, ha sido ampliamente documentada por Terrasa Mateu (2016, pp. 440-509). En la novela gráfica, se hace eco de esta realidad el personaje de "El morito", al que ya hemos aludido.

La violencia contra homosexuales no se circunscribía únicamente al marco legislativo y al Estado. El sistema jurídico predominante de la época señalaba la necesidad de "curar" y reeducar a los homosexuales mediante las técnicas médicas adecuadas. Estas eran normalmente las técnicas agresivas de modificación de la conducta, como el electroshock (Ugarte, 2008, p. 71) $)^{9}$ : la novela gráfica se refiere en varias ocasiones a estos tratamientos, puesto que el discurso médico y psiquiátrico hegemónico durante el franquismo consideraba al homosexual como un delincuente y/o un enfermo contagioso, habida cuenta de la "homofobia visceral y unos profundos y arraigados prejuicios antihomosexuales" que marcaron la psiquiatría del franquismo (Adam Donat y Martínez Vidal, 2008, p. 135).

No de menor importancia resultaba el control social ejercido por la Iglesia, el cual también observamos en el cómic: cuando Bruno decide contarle a su tía Julia que es homosexual, esta decide pedir ayuda a una monja, quien lo delata a la policía. La connivencia y la colaboración entre el régimen franquista y la Iglesia era manifiesta y dio origen al llamado "nacionalcatolicismo", una institucionalización de la moral y las costumbres para intervenir en la vida cotidiana (Mora Gaspar, 2016, p. 39).

En último lugar, otro elemento represivo simbólico clave es el modelo de masculinidad del franquismo. Este modelo, inicialmente influido por las ideas fascistas, se basaba en una exacerbación y una idealización de la virilidad (cuerpo atlético, dinamismo), así como un refuerzo de la separación sexual del trabajo (trabajo remunerado-hombre, trabajo doméstico-mujer), en consonancia con el militarismo de los fascismos del siglo XX, y 
del binomio público-privado (masculino-femenino). Según Mary Vincent, el modelo de masculinidad franquista evolucionó a un "paternalismo [que] dependía de la autoridad masculina, pero [que] ni era militar ni tenía que ser violento" (Vincent, 2006, p. 147). En consecuencia, este modelo de virilidad creaba espacios de camaradería masculina muy sólidos, especialmente en estamentos militarizados. Como ya hemos advertido, el miedo a que esos espacios de camaradería derivasen en actos y/o relaciones homosexuales ${ }^{10}$ constituye el principal argumento para considerar al homosexual como uno de los enemigos internos a eliminar, especialmente cuando el régimen franquista no contaba con enemigos exteriores claros (Pérez Sánchez, 2007, p. 12).

En El Violeta encontramos este modelo de masculinidad paternalista y de camaradería masculina claramente personificado en el padre de Bruno, un policía de la secreta que pretende "enderezar" la vida de su hijo tras ser arrestado por homosexual. Su particular terapia para "curar" la homosexualidad de Bruno consiste en el reconocimiento, en primer lugar, de que esta está motivada por la ausencia de una figura paterna durante su infancia. En segundo lugar, pretende "convertirlo en un hombre" mediante el ingreso en la policía, a través de una educación autoritaria y violenta, el ejercicio físico y el deporte, el consumo de alcohol y, posteriormente, el matrimonio con Maricruz, hija del capitán. En otras palabras, la asimilación a un modelo de vida masculino, viril, autoritario, paternalista, centrado en un trabajo digno, legal y una vida familiar heterosexual y, por tanto, contrario al afeminamiento, la sensibilidad y el trabajo burocrático en la contabilidad de la empresa familiar. En definitiva, la homosexualidad se conceptualiza como un enemigo interno que corrompe las esencias y buenas costumbres españolas, capaz de infiltrarse en todo tipo de instituciones y cuya erradicación requiere de diferentes mecanismos y medidas que se reflejan en el cómic: la represión y criminalización, mediante la ley y los cuerpos de seguridad del estado; la patologización, por medio de la medicina y la psicología; y la condena moral y el control social de la vida íntima, a través de la Iglesia.

\section{Memoria de dos estrategias ante la represión}

A lo largo de la novela gráfica y mediante el desarrollo vital del protagonista, Bruno, y su contrapunto, Julián, se produce un paralelismo entre dos estrategias de supervivencia a la represión sexuada. Por un lado, Bruno representa una vía de acomodación e integración en el franquismo, no siendo consciente de que su estrategia de "armario" y doble vida, al mismo tiempo que le ofrecía ciertas garantías de protección, le impedía "la superación individualizada del estigma para obtener una red de apoyo” (Gómez Beltrán, 2018, p. 430) y lo condenaba a una fuerte frustración tanto a él como a su entorno familiar. Recrear este escenario de infelicidad era uno de los objetivos que pretendía el guionista Juan Sepúlve$\mathrm{da}^{11}$. Por otro lado, el personaje de Julián nos ofrece una vía de resistencia a los elementos más descarnados de la represión ${ }^{12}$.

Con respecto a Bruno, la acomodación se produce en diferentes órdenes: el laboral, con el ingreso en la policía; el social, pues prácticamente no teje amistad con ningún otro homosexual y participa en redadas contra homosexuales; el familiar, con el matrimonio con 
Maricruz y la educación autoritaria de su hijo, calcando el modelo de educación paternalista y autoritaria de su padre; y, por último, el ideológico, mediante la ocultación y represión del deseo homosexual cuando confunde el acercamiento de un colega de la comisaría con una insinuación homosexual. De hecho, Bruno, después de percatarse del error, propone someterse a terapias de electroshock para curarse de la homosexualidad, aunque al final su tía se lo impide. El culmen de este proceso de acomodación ideológica al régimen franquista por parte de Bruno se da especialmente al final, con la renuncia al exilio (a la vida con Julián) y el regreso a la vida matrimonial (y al "armario") que se observa en las últimas páginas de la novela gráfica, en las cuales se deduce, por un lado, una apuesta clara por el cuidado de la relación matrimonial (la compra de turrones y flores para su mujer) y, por otro lado, la negativa a participar en cualquier acto de disidencia al pasar de largo por una manifestación que pedía libertad y en la que participaban colectivos homosexuales. Esta acomodación se muestra como un proceso no exento de contradicciones, ya que Bruno, tras llevar a cabo una redada contra homosexuales, debe interrogar a Anselmo, su excompañero de celda homosexual y quien lo había ayudado durante su estancia en la cárcel13. La escena del interrogatorio muestra su evolución vital e identitaria: si al inicio de la novela se situaba en el lugar del homosexual represaliado por el régimen, ahora él mismo forma parte del aparato represor que, a su vez, le proporciona las condiciones materiales para llevar una doble vida. En otras palabras, la acomodación al régimen franquista es paulatina y manifiesta ciertas aristas, pues el protagonista muestra alguna resistencia al modelo heterosexista, especialmente con respecto al "abandono" de los actos homosexuales, al mantener varios encuentros sexuales con Julián y con desconocidos en bares.

El último encuentro con Julián muestra con desgarro la contradicción vital de Bruno, ya que Julián le ofrece la posibilidad real, ya no como un sueño, de vivir libremente su relación homosexual exiliándose en México. Tras un debate interno, Bruno idea una estrategia (fallida) para poder exiliarse con Julián. El fracaso de esta estrategia, por culpa de otro miembro de la policía, supone el cierre de toda posibilidad de resistencia y/o libertad sexual desde la perspectiva del personaje de Bruno.

El personaje de Julián supone, como hemos dicho, un contrapunto al de Bruno: si este representa a la clase media urbana, aquel pertenece a una clase social baja (hijo de agricultores), sin posibilidades laborales y sociales de mejora. También a diferencia de Bruno, que consigue salir de la cárcel gracias a su padre ${ }^{14}$, Julián sufre la represión más brutal del franquismo contra los homosexuales en el campo de concentración de Tefía. Más tarde, asume asimismo una resistencia política, convirtiéndose en uno de los comunistas más destacados. En definitiva, y como avanzábamos al inicio de este capítulo, Julián asume su identidad homosexual como un lugar de resistencia que lo empodera y lo dota de mayor autonomía vital (Gómez Beltrán, 2018, p. 440).

\section{Conclusión}

A través del paralelismo establecido entre las dos estrategias encarnadas por Bruno y Julián, personajes principales en torno a los cuales pivota una amplia galería de personajes 
secundarios, El Violeta ofrece una memoria ficcionalizada de una experiencia colectiva real, pues muchos episodios de la represión franquista recogidos en este cómic se basan en un compendio de testimonios y documentos de ex presos sociales. Ya hemos adelantado que, atendiendo a la propuesta de Fernández de Arriba (2015, p. 17), la novela gráfica corresponde globalmente a lo que este estudioso denomina "memoria recreada": no se trata de una memoria individual, relativa a una persona concreta y vinculada biográficamente a los autores, sino de un abanico de testimonios de homosexuales que, en determinadas escenas o pasajes, corresponden a la memoria de un represaliado específico. Así, centrándonos solamente en los coprotagonistas, el inicio de la historia, situada en Valencia, con la delación de Bruno por una monja, responde claramente a la biografía de Antoni Ruiz (Ruiz, 2004). Por otra parte, los pasajes relacionados con Tefía han sido recreados en la ficción teniendo en cuenta los testimonios de Octavio García y Juan Curbelo, supervivientes del campo de concentración (Sepúlveda, 2018).

Esa ficcionalización de un conjunto amplio de testimonios representativos de una vivencia común, compartida por los aproximadamente cinco mil homosexuales represaliados durante el franquismo, así como la personificación de dos estrategias de supervivencia al régimen, con la disidencia o con la "armarización", convierten a El Violeta en un vehículo de expresión de una voz y una experiencia colectiva homosexual atravesada por la represión sexuada, cuyas víctimas no han sido reparadas justamente y cuyos testimonios han sido silenciados o invisibilizados en gran medida a lo largo de la historia democrática española. El contexto social en el que se publica la novela gráfica la dota, además, de una mayor trascendencia, dada la serie de insuficiencias que hemos visto en lo concerniente a la recuperación de la memoria histórica LGTB, tanto en la reparación de las víctimas de la represión franquista por cuestión de orientación sexual o identidad de género como, especialmente, en el cuidado de los lugares de la memoria histórica más destacados para dicha comunidad.

Este abandono y dejación institucional otorga un valor importante a los artefactos culturales que rescatan del olvido testimonios y experiencias del franquismo. En consecuencia, El Violeta no solo recupera, difunde y con-memora los antedichos lugares de la memoria sino que el cómic, en sí mismo, como producto discursivo y cultural, se erige en un lugar de la memoria simbólico que, en la medida de lo posible, procura reparar a las víctimas y recoger una experiencia colectiva marcada por la represión que atravesó las vidas de quienes ofrecieron algún tipo de resistencia y de quienes optaron por intentar sobrevivir como fuera, aunque eso implicara vivir una vida de infelicidad y autoodio.

\section{Notas}

1. La cita se halla en el capítulo 11 del libro de Fernando Sánchez Marcos, consagrado a la "Cultura histórica y memoria en el mundo actual". Según se aclara en una nota al pie (Sánchez Marcos, 2012, p. 177), dicho capítulo está escrito conjuntamente con Fernando Sánchez Costa. 
2. Un ejemplo pionero lo proporciona la serie autobiográfica Paracuellos, de Carlos Giménez, cuya primera entrega se dio a conocer en la revista Muchas gracias en una fecha tan temprana como es el año 1976.

3. Diario de sesiones del Congreso de los Diputados (15/12/2005, n.o 59, p. 2756), disponible en congreso.es/public_oficiales/L8/CONG/DS/PL/PL_059.PDF (consultado el 23/2/2020).

4. Un comunicado de prensa de la Asociación de Ex-Presos Sociales, del 22 de noviembre de 2011, cifraba en 100 el número de solicitudes de indemnización que habían sido resueltas favorablemente, lo que supone un 62,5 por ciento de las tramitadas hasta entonces (expresos-sociales.blogspot.com/p/notas-de-prensa.html, consultado el 24/2/2020). En esa misma dirección puede leerse una nota de prensa de octubre de 2012 relativa a la primera lesbiana represaliada en la dictadura que solicitaba la indemnización a la que tenía derecho.

5. Se entiende homosexuales varones principalmente, ya que la homosexualidad femenina no era ni contemplada por el fuerte machismo y la represión de la sexualidad femenina, como prueba la práctica inexistencia de detenciones de mujeres por actos de homosexualidad (Galván, 2017, p. 70). Asimismo, el término "homosexuales" hace referencia también a "comportamientos desviados"; es decir, a toda una serie de identidades trans y de prácticas como el travestismo.

6. Esta ley se aprobó en 1970, a pesar de que en el cómic se haga referencia a ella en la década de los 50 .

7. El régimen franquista llegó a crear en 1967 la Central de Observación que, entre otras tareas, analizó a 200 homosexuales delincuentes, y cuya misión consistía en dictaminar mediante supuestas pruebas científicas el predominio sexual de los presos: activo, pasivo o mixto (Mora Gaspar, 2016, pp. 153-154).

8. En sentido estricto no se trataría de un campo de concentración, a pesar de que el régimen franquista usó frecuentemente esa nomenclatura.

9. Existen referencias de algunas prácticas muy puntuales de lobotomía en la cárcel de Carabanchel (Mora Gaspar, 2016, p. 166).

10. En este sentido, la relectura en clave homosexual de varias obras del franquismo, en especial de A mí la legión, corrobora la potencialidad de los espacios de camaradería masculina como lugares susceptibles de ser leídos en clave homoerótica (Navarrete-Galiano, 2011).

11. Así lo plasma en una entrevista concedida a eldiario.es: "Me pareció muy interesante la historia de los homosexuales que trataron de encajar en la España de Franco. Sobre todo los que se hicieron pasar por heterosexuales. Las vidas paralelas que llevaron y la infelicidad que esta mentira causó en sus familias" (Sepúlveda, 2018).

12. El guionista principal pretende rendir un homenaje con el personaje de Julián, como explicita en la misma entrevista (Sepúlveda, 2018): "quería que representase a los homosexuales más valientes. Los que pelean en todas las batallas contra la intolerancia. Quería contar el precio que pagaron todos aquellos que desafiaron al régimen sin importarles las consecuencias".

13. Las estancias en cárceles también comportaban la creación de lazos de amistad con otros homosexuales presos (Huard, 2016, p. 140). 
14. La policía y el sistema judicial castigaban más severamente a las clases populares, exonerando en muchas ocasiones de la represión a la clase media o burgueses (Huard, 2016; Terrasa Mateu, 2008; Ugarte, 2008).

\section{Bibliografía}

Abad, I. (2009). Las dimensiones de la "represión sexuada" durante la dictadura franquista. Revista de historia Jerónimo Zurita, 84, 65-86.

Adam Donat, A. y Martínez Vidal, À. (2008). "Infanticidas, violadores, homosexuales y pervertidos de todas las categorías": la homosexualidad en la psiquiatría del franquismo. En J. Ugarte Pérez (coord.). Una discriminación universal. La homosexualidad bajo el franquismo y la Transición (pp. 109-138). Barcelona: Egales.

Alary, V. (2016). La Guerra Civil española vista desde la historieta. Diablotexto Digital. Revista de crítica literaria, 1 (monográfico Historieta y sociedad), 6-28. doi: 10.7203/ diablotexto.1.8911

Bórquez, N. (2016). La historieta de la memoria: la Guerra Civil y el franquismo en viñetas. Diablotexto Digital. Revista de crítica literaria, 1 (monográfico Historieta y sociedad), 2941. doi: 10.7203/diablotexto.1.8853

Caetano Pira, L. (2018, 16 de junio). Los triángulos rosas españoles. El Salto. Consultado en elsaltodiario.com/memoria-historica/triangulos-rosas-espanoles-homofobia-transfobiadurante-franquismo (1/3/2020).

Casanova, J. (2014, 21 de mayo [2007]). El lugar de la memoria en el cine de Carlos Saura. Consultado en juliancasanova.es/el-lugar-de-la-memoria-en-el-cine-de-carlos-saura/ $(28 / 1 / 2020)$.

Colmeiro, J. F. (2005). Memoria histórica e identidad cultural. De la postguerra a la postmodernidad. Rubí (Barcelona): Anthropos.

De la Fuente Soler, M. (2011). La memoria en viñetas: historia y tendencias del cómic autobiográfico. Signa, 20, 259-276. doi: 10.5944/signa.vol20.2011.6267

Erice Sebares, F. (2008). Memoria histórica y deber de memoria: las dimensiones mundanas de un debate académico. Entelequia. Revista Interdisciplinar, 7 (monográfico La memoria como conflicto. Memoria e historia de la Guerra Civil y el Franquismo), 77-96. Consultado en revistaentelequia.wordpress.com/blog/numero-7/ (21/2/2020).

Fernández Asperilla, A. (2005). Franquismo, delincuencia y cambio social. Espacio, Tiempo y Forma, V (serie "Historia Contemporánea"), 17. doi: 10.5944/etfv.17.2005.3115

Fernández de Arriba, D. (2015). La memoria del exilio a través del cómic: Un largo silencio, El arte de volar y Los surcos del azar. CuCo. Cuadernos de cómic, 4, 7-33. Consultado en cuadernosdecomic.com/docs/revista4/memoria_historica.pdf (22/2/2020).

Fernández de Arriba, D. (coord.) (2019 [2018]). Memoria y viñetas. La memoria histórica en el aula a través del cómic ( 2 a ed. en esp.). Valencia: Desfiladero Ediciones.

Fernández-Paradas, A.-R. (2020). Patrimonio y memoria LGTBI en las leyes autonómicas en España. El profesional de la información, 29 (1), 1-15. doi: 10.3145/epi.2020.ene.10 
Galván, V. (2017). De vagos y maleantes a peligrosos sociales: cuando la homosexualidad dejó de ser un delito en España (1970-1979). Daimon. Revista Internacional de Filosofía, 6 (suplemento), 67-82. doi: 10.6018/daimon/290891

García, S. (2010). La novela gráfica. Bilbao: Astiberri.

Gómez Beltrán, I. (2018). La despenalización identitaria y la amnistía política masculina en la España de la Transición democrática: movimiento feminista y LGTB. Arenal. Revista de historia de las mujeres, 25, 425-442. doi: 10.30827/arenal.v25i2.5231

Gual Boronat, Ó. (2013). Viñetas de posguerra. Los cómics como fuente para el estudio de la historia. Valencia: Universitat de València.

Gutiérrez Dorado, A. (2008). La voz de la memoria. En J. Ugarte Pérez (coord.). Una discriminación universal. La homosexualidad bajo el franquismo y la Transición (pp. 247-256). Barcelona: Egales.

Huard, G. (2016). Los homosexuales en Barcelona bajo el franquismo. Prostitución, clase social y visibilidad entre 1956 y 1980. Franquisme \& Transició. Revista d'Història i de Cultura, 4, 127-151. doi: 10.7238/fit.v0i4.2442

Huard, G. (2019). Spain from Franco's Repressive Regime to Same-Sex Marriage. En S. Brady y M. Seymour (eds.). From Sodomy Laws to Same-Sex Marriage. International Perspectives since 1789 (pp. 95-109). Londres et al.: Bloomsbury.

Juan-Navarro, S. y Torres-Pou, J. (2008). “Introducción”. En S. Juan-Navarro y J. Torres-Pou (eds.). Memoria histórica, género e interdisciplinariedad. Los estudios culturales hispánicos en el siglo XXI (pp. 9-19). Madrid: Biblioteca Nueva.

Martín Sánchez, M. (2011). Aproximación histórica al tratamiento jurídico y social dado a la homosexualidad en Europa. Estudios constitucionales, 9 (1), 245-276. doi:10.4067/ S0718-52002011000100009

Matly, M. (2014). El cómic español y la Guerra Civil: Transición y primera década de democracia - 1976-1992. Tebeosfera, 2a época (12). Consultado en tebeosfera.com/docu mentos/el_comic_espanol_y_la_guerra_civil_transicion_y_primera_decada_de_demo cracia_-_1976-1992.html\#_ftnref13 (14/2/2020).

Monferrer Tomàs, J. (2003). La construcción de la protesta en el movimiento gay español: la Ley de la Peligrosidad Social (1970) como factor precipitante de la acción colectiva. Reis. Revista Española de Investigaciones Sociológicas, 102, 171-204. Consultado en jstor. org/stable/40184541 (19/1/2020).

Mora Gaspar, V. (2016). Al margen de la naturaleza. La persecución de la homosexualidad durante el franquismo. Leyes, terapias y condenas. Barcelona: Debate.

Navarrete-Galiano, R. (2011). Conceptualización de lo queer en ¡A míla legión!. Relecturas de la filmografía franquista. Icono14, 9 (3), 346-360. doi: 10.7195/ri14.v9i3.17

Nonnenmacher, H. (2006). La memoria del franquismo en el cómic español. En U. Winter (ed.). Lugares de memoria de la Guerra Civil y el franquismo. Representaciones literarias y visuales (pp. 177-208). Frankfurt/Madrid: Vervuert/Iberoamericana.

Pérez Sánchez, G. (2004). El franquismo, ¿un régimen homosexual? Orientaciones: revista de homosexualidades, 7, 29-50.

Pérez Sánchez, G. (2007). Queer transitions in contemporary Spanish culture. From Franco to la Movida. Albany: State University Press of New York Press. 
Reig Tapia, A. (2009). Cultura política y vía pacífica a la democracia. El miedo y el olvido en la transición española. En I. Olmos y N. Keiholz-Rühle (eds.). La cultura de la memoria. La memoria histórica en España y Alemania (pp. 107-127). Madrid/Frankfurt: Iberoamericana/Vervuert.

Resina, J. R. y Winter, U. (2017 [2005]). Un nuevo prefacio. En J. R. Resina y U. Winter (eds.). Casa encantada. Lugares de la memoria en la España constitucional (1978-2004) (2a ed., pp. I-VIII). Frankfurt/Madrid: Vervuert/Iberoamericana.

Ruiz Mantilla, J. (2013, 12 de mayo). Humillados por diferentes. El País. Consultado en elpais.com/elpais/2013/05/10/eps/1368188535_439636.html (1/3/2020).

Ruiz, A. (2004, 20 de diciembre). Una monja me delató a la Brigada Criminal. El País. Consultado en elpais.com/diario/2004/12/20/sociedad/1103497201_850215.html (9/2/2020).

Ruiz, A. (2018, 10 de octubre). Queremos que las personas LGTB represaliadas por el franquismo tengan una pensión digna [entrevista con Pablo Castaño]. Contexto y acción, 190. Consultado en ctxt.es/es/20181010/Politica/21259/Expresos-sociales-Antoni-RuizLGTB-franquismo-memoria-Pablo-Castano.htm (24/2/2020).

Ruiz-Vargas, J. M. (2008). ¿De qué hablamos cuando hablamos de 'memoria histórica'? Reflexiones desde la Psicología cognitiva. Entelequia. Revista Interdisciplinar, 7 (monográfico La memoria como conflicto... ), 23-76. Consultado en revistaentelequia.wordpress. com/blog/numero-7/ (23/2/2020).

Sánchez Marcos, F. (2012). Las huellas del futuro. Historiografía y cultura histórica en el siglo $X X$. Barcelona: Universitat de Barcelona.

Sepúlveda Sanchis, J.; Santos Mercero, A. y Cochet, M. (2019 [2018]). El Violeta (2a ed.). Fuenlabrada (Madrid): Drakul.

Sepúlveda [Sanchis], J. (2018, 16 de diciembre). La represión de los homosexuales durante el franquismo en Fuerteventura salta al cómic [entrevista con Eloy Mora]. Consultado en eldiario.es/canariasahora/sociedad/represion-homosexuales-franquismo-Fuerteventurasalta_0_846565450.html (7/2/2020).

Serrano, M. (2017, 11 de febrero). El abandono de la vieja cárcel de Huelva, centro de represión homosexual durante el franquismo. Público. Consultado en publico.es/politica/ memoria-publica-abandono-vieja-carcel.html (12/2/2020).

Sevillano Calero, F. (2003). La construcción de la memoria y el olvido en la España democrática. Ayer. Revista de Historia Contemporánea, 52, 297-319.

Souto, L. C. y Martínez Rubio, J. (2016). Perspectivas, toma de conciencia y consolidación de la historieta en el mundo académico. Diablotexto Digital. Revista de crítica literaria, 1 (monográfico Historieta y sociedad), 1-5. doi: 10.7203/diablotexto.1.9033

Terrasa Mateu, J. (2008). La legislación represiva. En J. Ugarte Pérez (coord.). Una discriminación universal. La homosexualidad bajo el franquismo y la Transición (pp. 79-107). Barcelona: Egales.

Terrasa Mateu, J. (2016). Control, represión y reeducación de los homosexuales durante el franquismo y el inicio de la Transición. (Tesis doctoral. Universitat de Barcelona). Consultado en hdl.handle.net/10803/398003 (28/1/2020).

Ugarte, J. (2008). Las bases ideológicas de la represión. En J. Ugarte Pérez (coord.). Una discriminación universal. La homosexualidad bajo el franquismo y la Transición (pp. 4978). Barcelona: Egales. 
Vallès Muñío, D. (2017). La privación de libertad de los homosexuales en el franquismo y su asimilación al alta en la Seguridad Social. IUSLabor, 1, 2017, 1-13.

Vincent, M. (2006). La reafirmación de la masculinidad en la cruzada franquista. Cuadernos de historia contemporánea, 28, 135-151.

\begin{abstract}
This paper aims to show how the graphic novel entitled El Violeta (2019) is an interesting example of the dialogue between the artistic medium of comics, historical memory, and LGBT activism, as it creates a collective homosexual experience of Francoism that is particularly relevant in the current context of discussions on Spain's recent past. Based on various individual testimonies, this graphic novel undertakes a fictional reconstruction of the physical and symbolic violence perpetrated by the Franco regime, thus creating a narrative place of memory of a common traumatic experience, often silenced or made invisible. In this way, El Violeta contributes to shaping the historical memory of the homosexuals who suffered under the Spanish dictatorship, since it conveys, through the language of the comic art form, the repressive homophobia of the Franco regime. In the absence of a complete legal and institutional reparation, it therefore contains at least an attempt at symbolic recognition on the socio-cultural level.
\end{abstract}

Keywords: homosexuality - repression - comics - historical memory - testimony.

Resumo: Este trabalho tenciona mostrar como o romance gráfico El Violeta (2019) constitui um interessante exemplo de diálogo entre o meio artístico da banda desenhada, a memória histórica e o ativismo LGTB, ao gerar uma experiência coletiva homossexual do franquismo que resulta particularmente oportuna no contexto de debate em torno do passado recente que vive a sociedade espanhola na atualidade. A partir de diversos depoimentos individuais, $E l$ Violeta empreende uma reconstrução ficcional da violência física e simbólica exercida pelo regime franquista que conforma um lugar da memória narrativo de uma experiência traumática comum, não raro silenciada ou invisibilizada. A obra aqui analisada contribui, assim sendo, para a configuração da memória histórica dos homossexuais que sofreram a ditadura, refletindo mediante a linguagem da $\mathrm{BD}$ a homofobia repressiva do regime. Desse modo, na ausência de uma plena reparação jurídica e institucional, supõe pelo menos uma tentativa de reconhecimento simbólico no plano sociocultural.

Palavras chave: homossexualidade - repressão - quadrinhos - memória histórica - testemunho.

[Las traducciones de los abstracts fueron supervisadas por el autor de cada artículo] 